\title{
CORRIGENDUM
}

\section{No association of alcohol use and the risk of ulcerative colitis or Crohn's disease: data from a European Prospective cohort study (EPIC)}

MM Bergmann, V Hernandez, W Bernigau, H Boeing, SSM Chan, R Luben, K-T Khaw, F van Schaik, B Oldenburg, B Bueno-de-Mesquita, K Overvad, D Palli, G Masala, F Carbonnel, M-C Boutron-Ruault, A Olsen, A Tjonneland, R Kaaks, V Katzke, E Riboli and AR Hart

Correction to: European Journal of Clinical Nutrition (2017) 71, 512-518; doi:10.1038/ejcn.2016.271; published online 25 January 2017

Since the publication of this article, the authors have noticed an error in author affiliation 1. The correct affiliation is:
Department of Epidemiology, German Institute of Human Nutrition, Potsdam, Germany.

The PDF and html versions have been amended. The authors apologise for any inconvenience caused. 